\title{
Factors Influencing Small and Medium Enterprises (SMEs) in Adoption and Use of Technology in Cote d'Ivoire
}

\author{
Diabate Ardjouman ${ }^{1}$ \\ ${ }^{1}$ School of Management, Shanghai University \\ Correspondence: Diabate Ardjouman, School of Management, Shanghai University, 99 Shangda road, Shanghai \\ city, China. E-mail: diabateardjouman@yahoo.fr
}

Received: April 30, 2014

Accepted: June 11, 2014

Online Published: July 25, 2014

doi:10.5539/ijbm.v9n8p179

URL: http://dx.doi.org/10.5539/ijbm.v9n8p179

\begin{abstract}
This paper examines factors hindering and possible solutions available during adoption and use of technology for sustainable development and management of SMEs in Cote d'Ivoire, arising from the fact that technologies have not been put into the mainstream of management while analyzing the possibilities of mainstreaming SMEs goals into Cote d'Ivoire development agenda. This study was anchored on management theory and the technological determination theory

The study adopted a descriptive survey research design. Data was collected from 200 respondents with the aid of a questionnaire. The respondents of this study included 50 senior executives, 50 middle-level managers and 100 workers in Abidjan city, purposively selected from SMEs in service and manufacturing industries. Data collected was analyzed by use of descriptive and inferential statistical techniques after which results were presented in tables.

The findings of the study reveal that there is a high level of awareness of the importance of technology in management of SMEs; ICTs and other technologies can be mainstreamed into SMEs development agenda and that technology is a veritable tool for sustainable development of SMEs in Cote d'Ivoire. Therefore, this study recommends that leaders of SMEs in Cote d'Ivoire formulate and implement policies that would enhance the development and deployment of technology in SMEs with the aim of bridging the digital divide in a bid to actualize sustainable development in the country.
\end{abstract}

Keywords: adoption and use, Cote d'Ivoire, factors influencing, SMEs, technology

\section{Introduction}

All over the African continent, policies, programs, projects and plans are formulated to improve lives of citizens-empowering the people, which are the core aims of development. Sadly, most of these policies, programs, projects and plans formulated are of short term purposes and are not totally implemented. Furthermore, they do not highlight all aspects of development which includes technology, education, agriculture, health among others. Consequently, it becomes hard for African countries to get to a stage where they can be referred to as developed countries. African countries can only be developed if and only if they work towards sustainable development through embracing technology in management of its SMEs.

According to Thiam (2009), sustainable development is a global crusade movement, which is a process rather than an end goal. Green (2011) noted that this process requires constant analysis and evaluation of the emerging trends in the discussion so as to take the issue of technology and sustainable development to the next level. Sustainable development is the process of ensuring that the present development is maintained and sustained for the present and future. It focuses on building the nation for the future in order to improve the lives of its citizens. To sustain and achieve sustainable development, reliable, potential and revolutionary efficient tools must be employed. These technological tools are the ICTs such as the mobile phones, microcomputers, e-mail, Internet among others. It is with this background a study to investigate factors influencing small and medium enterprises (SMEs) in adoption and use of technology in Cote d'Ivoire was conceptualized.

The current study was formulated to investigate SMEs employees and management attitudes and perceptions towards adoption and use of technology in their businesses, with a purpose of establishing factors hindering its adoption and use by small and medium enterprises, for sustainable development in Cote d'Ivoire. 
The study was guided by the following objectives:

- To determine perceptions of employees and management of SMEs towards adoption and use of technology.

- To examine factors hindering SMEs in adoption and use of technology.

- To establish how to overcome factors hindering effective adoption and use of technology by SMEs.

Findings and recommendation of this research are expected to assist researchers, academicians and other stakeholders in broadening of the syllabus, hence providing a deeper understanding on factors hindering adoption and use of technology by SMEs in order to improve their performance. The findings of this study are expected to help SMEs in Cote d'Ivoire and others, with an insight into the benefits of adoption and use of sound technology that can help maximize their margins. Further, findings of the study are expected to help planners and policy makers strengthen or adjust the position in businesses policy formulation.

\section{Literature Review}

It is widely accepted that SMEs are the backbone of modern market economies, thus play an important role particularly in developing countries. In most countries, SMEs are the dominant form of business organizations, accounting for over $90 \%$ of the business population, and they play a key role in driving sustainable economic growth and job creation. Bringing SMEs up to speed with the digital revolution is not just a matter of improving their quarterly profits, but also about creating growth and jobs. In the digital age, no business can thrive without better use of ICT. Kozak, (2011) emphasized that SMEs grow two to three times faster when they embrace technology.

ICT is not just a policy buzzword but a great enabler for businesses, regardless of size or activity sector. Whether it is a tech start up or a provider of traditional products or services, thanks to capabilities such as the use of social networks, cloud-based services and data analytics SMEs can expand their business reach to new clients and markets.

\subsection{Definition of SMEs}

Defining small and medium enterprises (SMEs) is not a simple task. This is because there are much different definitions as there are interlocutors. Given that SMEs reality and size can a lot from sector to sector, or according to economy and timeframe considered, a single definition is not easy (Vilasea, 2013). Actually, there is no commonly accepted definition of SMEs; many times they are described with number of employees or annual turnover. In fact, definitions vary with the level of particular economy in consideration. For example, in developed countries, like in Europe or America, where there is a larger variation in enterprise types, small-sized company can be considered medium or large in less developed countries like in Cote d'Ivoire.

Internationally, it is only European Union that have taken some steps in adopting a common accepted definition of SMEs, though there are still debate among countries in the block. Way back in 2003, the commission of European Union adopted a definition of micro, small and medium-sized enterprises, which provides a framework for defining SMEs as shown in Table 1.

Table 1. Definition of micro, small and medium sized enterprises by European commission

\begin{tabular}{llll}
\hline Enterprise Type Sheet & No. of Employees & Turnover & Balance \\
\hline Micro & $<10$ & $\leq € 2$ million & $\leq € 2$ Million \\
Small & $<50$ & $\leq € 10$ million & $\leq € 10$ million \\
Medium-sized & $<250$ & $\leq € 50$ million & $\leq € 43$ million \\
\hline
\end{tabular}

In simple terms, European Commission defined SMEs as enterprises with less than 250 workers. With respect to fiscal criteria, finances cannot exceed $€ 50$ million as a turnover, and/or $€ 43$ million on a balance sheet. In addition, the Commission of European Community specifies terms of ownership, reporting that SMEs ought to be independent, with less than $25 \%$ of it being owned by outside interest (Kozak, 2011).

Due to different definitions of SMEs, it is important to develop a working definition that can effectively support technological needs, or the purpose of the given task. This paper adopted a definition developed by Cote d'Ivoire SME Charter by Cote d'Ivoire policy makers in January 2012. The purpose for adopting this definition is because of consensus among diverse stakeholders and as a result of sum of previous experiences in finding unified relevant identification of SMEs in the literature. 
According to Cote d'Ivoire SME charter, SMEs are characterized as physical or moral persons producing market goods or services. In addition, employees must be engaged in full-time, be awarded a contract for work and registered with the National Social Security Fund.

There are three wide parameters which define SMEs in Cote d'Ivoire:

The category of micro-entities with:

- Annual revenue (without tax) not exceeding $€ 45,753$;

- $\quad$ less than 10 employees;

The category of small-sized enterprises characterized by following:

- Annual turnover between $€ 45,753$ - $€ 228,674$;

- less than 50 employees;

The category of medium-sized business with:

- Annual revenue (without tax) between $€ 228,674$ - $€ 1,524,490$;

- $\quad$ Up to 200 employees;

Table2. Definition of SMEs by Cote d'ivoire SME charter

\begin{tabular}{lll}
\hline Enterprise Type Sheet & No. of Employees & Turnover \\
\hline Micro & $<10$ & $\mathrm{X} 0 \mathrm{~F} 30,000,000$ or $€ 45,735$ \\
Small & $<50$ & $(\mathrm{X} 0 \mathrm{~F} 30,000,000 \mathrm{X} ; \mathrm{OF} 150,000,000)$ or $(€ 45,735 ; € 228,674)$ \\
Medium-sized & $<200$ & $(\mathrm{X} 0 \mathrm{~F} 150,000,000 ; \mathrm{XOF} 1,000,000,000)$ or $(€ 228,674 ; € 1,524,490)$ \\
\hline
\end{tabular}

\subsection{Benefit of SMEs in National Economy}

Matlay and Weathead (2013) observed that SMEs are generally regarded as the 'backbone of the economy'. According to the authors, the business of SMEs constitute majority of economic growth and development in developing countries, like Cote d'Ivoire. SMEs make up $98 \%$ of registered companies, which account for almost $18 \%$ of the Cote d'Ivoire nation's gross domestic product, while in countries like Unites states boost of 99 percent of their firms being classified as SMEs, and 85\% in European Union (Sakal, 2012).

Several authors in Cote d'Ivoire continue to hold the view that the pool of resources that SMEs have, largely no impact in the economy and should be generally left to single sore proprietors or in the dark (Barun, 2011; Bate, 2011).

However, researchers have shown that SMEs employ large number of people and greatly contribute to the national income (Berger, 2012; Mingaine, 2013). In this regards, however, studies in China, USA, Kenya and other African countries show that contributions of SMEs are not the same across all the enterprises (Mingaine, 2013; Mutwiri \& Mingaine, 2014). According to Reynold (2010) those small enterprises which survive play a much more important role in National development. According to Bates (2011), only about one quarter of all SMEs account for most of the societal contributions in terms of out-of state exports, sales and employments.

\subsection{Characteristics of SMEs in Cote d'Ivoire}

In Cote d'Ivoire, SMEs tend to be closely parented to what is known as the informal sector. The informal is a large and diverse body of businesses and enterprises which share the common features of being hardly structured enterprises to modern companies. This sector offers a high number of employments to both rural and urban centers. The majority of formal SMEs originated from informal sectors. Actually, most of SMEs in Cote d'Ivoire still are under informal sector, which they tend to compose the high end. Therefore, most of them carry features of informal sector's behavior and culture.

According to Cote d'Ivoire charter on SMEs (2008), most of SMEs in Cote d'Ivoire are predominantly active in the food sector and craft industry in retail business and commerce. Due to rapid urbanization in the country, the SMEs have been provided with favorable environment to thrive. However, competition in this sector is extremely intense as there are little barriers for new entrants. This easy entry into the sector by any player, explains why the sector is occupied by many people in the country.

Another characteristic of this sector, as noted by Alila and Ove (2011) is low margins of profit. Due to low purchasing power of customers and high completion in SMEs, their profits margin tends to be low. Generally, 
equity of this sector is small due to the fact that owners have little resources to expand their business by adding more stock. The owners bring rather their own manpower and expertise. Due to this low equity, many financial institutions generally view these enterprises as an insufficient commitment of owners to the sector, hence curtailing the healthy relationships between them and banks. This explains why this sector needs a particular strategy different from what is generally applied by businesses of the modern economy.

According to Thiam (2009), most of SMEs have been defined by low level organization which is as a result of their sociological similarity with informal sector. African Development Bank (2004) noted that, large number of businesses in this sector is based on family structure and hence in one way or another use resources generated from the family connections to build and launch their business. The family acts as workforce, source of capital, or gives general support. Family premises are often or less used to operate this kind of business. Most of core businesses in this sector are based on personal expertise, most often are generally illiterate. Ghimire and Abo (2013) argue that the common way of acquiring expertise in this sector is generally through apprenticeship. Therefore, most of SMEs in Cote d'Ivoire rely more on apprentices and have little personnel.

\subsection{Adoption and Use of Technology by Small and Medium Enterprises (SMEs)}

Although studies on technology adoption and use comprise a considerable area of research within the ICT domain (Green, 2011), there continues to be a need for enhanced understanding of the factors influencing adoption and use of technology within the specific context of SMEs (Sakai, 2012). Several research related to SMEs imply a variety of descriptive variables influencing the adoption and use of technology, such as e-commerce, computerization of business, inter-organizational systems, etc. According to Vilaseca, (2013) lack of awareness and cost are critical elements in the general adoption and use of technology for SMEs. Lack of awareness contains numerous factors, which includes uncertainty of technology benefits, lack of guidance and unfamiliarity of technologies (Premkumar \& Roberts, 2010). According to Giovanni \& Mario, (2013) cost is mostly related to technological factors such as, training, maintenance costs, information systems and software. Barua, (2011) argues that lack of technology environment including lack of critical mass use, unavailability of ideal technology, e-business infrastructure are major external hindrances obstructing technology adoption and use by SMEs. Kirby \& Turner, (2012) observe that majority of external hindrances come from business related barriers.

Ritchie and Brindley (2010) noted that there are three barriers in adoption and use of technology by SMEs. These are: external pressures (requirements by trading partners and competitiveness from other players), organizational readiness and perceived benefits of the technology. The authors argue that perceived benefits form a key reason why many SMEs adopts and continues to use the technology. According to Giovanni and Mario (2013), most adoption and use frameworks look like a general framework using the technology, the capabilities of the organization and the external environment as its key explanatory variable.

According to Muraya (2009), external environment (suppliers, buyers, government interventions and competitive pressure) are very crucial factors influencing adoption and use of technology by many SMEs. The author suggests that environmental and organizational characteristics are required for proper implementation of technologies in SMEs businesses. Alila and Ove (2011) observed that, as primary external factor of the technology adoption and use, government role is a very important factor in the integration of the technology by SMEs. Most of government roles, the author notes, are related to financial supports including direct support of the development of application, tax breaks on technology infrastructure, etc.

According to Iacovou et al. (2009), SMEs need more financial support than big companies because of their structural characteristics such as: weakness of market power, lack of experience, etc. Vilaseca (2013) argue that due to the proliferation of ASPs and rapid development of a variety of technologies, outsourcing of technology is becoming suitable and is emerging as an influencing factor for many SMEs sectors.

Dixon et al. (2012) observed that cost of technology is an important influencing factor in the adoption and use of technology by many SMEs. The authors argue that SMEs will less likely adopt and use technology when its initial set-up cost is high. Matlay and Weathead (2013) noted that many SMEs in Africa often have much difficulty when outsourcing for financial support. Therefore, adoption and use of new technologies may be considered too expensive by these enterprises because of their lack of financial support. According to Paul and Pascale (2013), many SMEs in Africa face specific problems in the formulation of innovations strategies because of limited range of technological competencies and limited financial resources.

A study conducted by Ghimire and Abo (2013) on unlocking the potential of small and medium enterprises in West Africa reveals that adoption and use of technology by SMEs depended on the owner being the decision-maker. The findings from this study clearly indicated that technology adoption and use is positively 
related to enterprise size. The study concluded that organizations should determine level of skills and knowledge its employees have, because previous experiences and knowledge may influence organization decision in adopting and using the technology. The ability of the enterprise owner in technology skills and knowledge is definitely increasing the opportunity of adoption and use of the technology amongst SMEs. Thong and Yap (2011) established that SMEs owners are unlikely to adopt and use new and more sophisticated technologies if they are not familiar with the existing and basic ones. A study by Mingaine (2013) founded that there is limited number of employees with appropriate technical knowledge to adopt and use new technologies. The author argues that this lack of knowledge based employees may prevent or hinder adoption and use of the technology if the owner believes that it can on be implemented using specialist staff.

According to Mingaine (2013), external pressure from other trading partners is one of the significant predictors that has strong influence on SMEs in adoption and use of technology. The authors argue that without this external pressure, many SMEs owners may perceive adoption and use of technology as a waste of resources. This has an indication that many SMEs are not fully utilizing the technology in doing business. Parker (2010) points out that dependency on supplier/customer is closely related to external pressure to adopt and use technology. The author notes that when a major customer or supplier adopts new technology, the SME owner will more likely adopt and use the same technology. Iacovau et al. (2009) argue that SMEs are often forced to adopt and use technology by large companies. Hence, this might be a factor making SMEs to adopt and use technology if their trading partners force them.

In a study performed by Thong and Yap (2011), (2010) in Malaysia found that perceived benefits, government support and management support are important predictors that influenced SMEs to adopt and use technology. In another study, Paul and Pascale (2013), (2011) in Brunei identified factors influencing adoption and use of technology by SMEs as: perception of relative advantage, CEOs perception, CEOs characteristics, complexity, compatibility and organizational size. A study carried out by Sakai (2012) in Taiwan SMEs found that technical backing and computing skills were strong anchors of the perception of usefulness and exercise direct influence on adoption and use of the technology. Further study by Thong and Yap (2011), (2013) found that adoption and use of advanced technology was significantly related to innovativeness and advocated that innovativeness as a significant trait in determining technology adoption and use among SMEs in Taiwan.

\section{Conceptual Framework}

The current study focused on a conceptual framework essential in identifying factors influencing SMEs in adoption and use of technology in their businesses. The framework identifies the problem as lack of effective adoption and use of technology by SMEs due to challenges of cost, unreliable electricity supply, inadequate infrastructure, poor maintenance of technological infrastructures, government policies, negative attitude towards technology and lack of technical knowhow on technological instruments. Remedies are identified as establishing proper policies, expanding connections of electricity, exploring alternative sources of power and training of employees. Impacts are identified as improved business performance, improved communications, increased profit margins, increase innovations and increased areas of technology applications. 


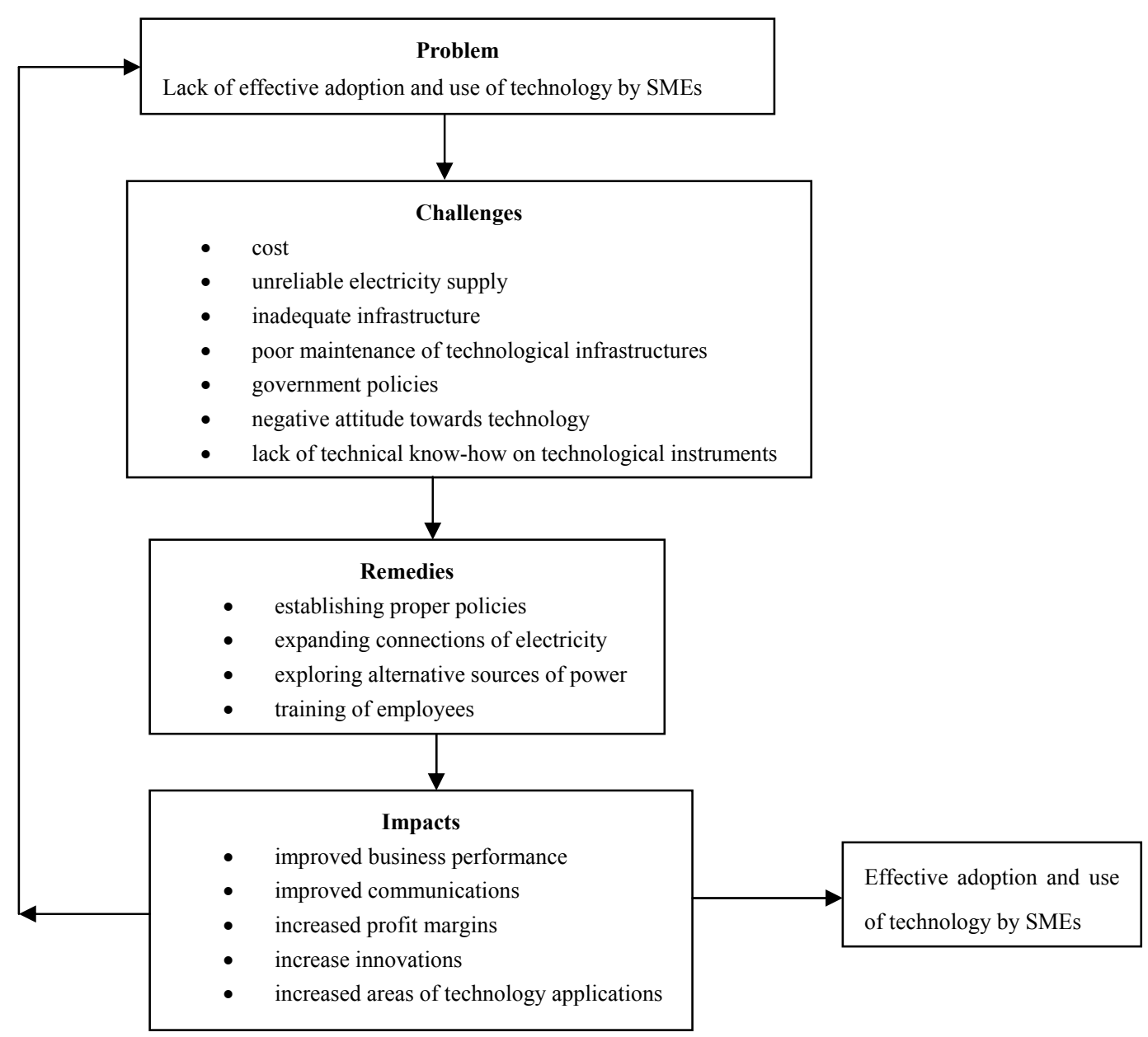

Figure1. Conceptual frame on adoption and use of technology by SMEs

\section{Research Methodology}

The current study adopted descriptive survey research design where responses and perception held by the respondents were studied. Descriptive survey research is used to investigate populations by selecting samples to discover and analyze occurrences at a particular point in time. Orodho (2008) argue that this form of research design provides quantitative descriptions of some part of the population.

This study was carried out among SMEs operating in Abidjan city of Cote d'Ivoire. The study involved 50 executive managers, 50 middle managers and 100 workers of SMEs found within the city. These SMEs were from varied background since the Abidjan city is occupied by people of different ethnic groups and their business are varied (retail, wholesale, community, communication, social, storage, personal service activities, transport, construction, hotel and restaurants and real estate and renting). The selection of the sample was done through use of stratified and simple random sampling techniques. Stratified sampling technique was used to ensure that the different sub-groups of SMEs were proportionally represented and their characteristics were accounted for.

The study used structured questionnaires for collecting data, which were designed to capture participants' perception and knowledge of adoption and use of technology in SMEs in Abidjan city. According to Koul (2012), questionnaires are used to offer considerable advantage in administration and present a better stimulus for a larger number of populations simultaneously and provide researchers with an easy way of gathering data.

Face and content validity of questionnaires was established by a panel of experts in the field of study. Gay (2002) argues that face and content validity is established by judgment of experts. This study relied on expert judgment of the members of the School of Management, Shanghai University and the supervisor on the validity of questionnaires. For establishing reliability of the research instruments, piloting was done in two SMEs which did not form part of this research. For ethical suitability of the study, research permit was acquired from the Ministry 
of Industry in Cote d'Ivoire. Assurance of confidentiality and written background on the research objectives was provided to the participants before commencement of the study.

\section{Findings and Discussions}

In this section, discussions and findings of this research is presented in tables according to specific themes of study. Also, references to pertinent studies in the literature and discussions of data collected are provided.

\subsection{Demographics of Participants in This Study}

On the gender of respondents, data collected showed that majority 125 (62.5\%) were males while females were $75(37.5 \%)$. These findings indicated that most of SMEs workers in Cote d'Ivoire were dominated by males. The data on age shows that majority of respondents were between $31-40$ years, $83(41.5 \%)$, followed by $41-50$ years at $52(26.0 \%)$, over 50 years were $38(19 \%)$ and less than 30 years were $27(13.5 \%)$. This data revealed most of age groups were represented in this study. As shown in table 3, most of participants had attained primary education.

Table 3. Demographics of participants in the study

\begin{tabular}{llll}
\hline Variable & Category & No. & $\%$ \\
\hline Gender & Males & 125 & 62.5 \\
& Females & 75 & 37.5 \\
\hline Age & Less than 30 & 27 & 13.5 \\
& $31-40$ & 83 & 41.5 \\
& $41-50$ & 52 & 26.0 \\
& Over 50 & 38 & 19.0 \\
\hline \multirow{2}{*}{ Level of education } & No schooling & 21 & 10.5 \\
& Primary & 97 & 48.5 \\
& Secondary & 69 & 34.5 \\
& University & 13 & 6.5 \\
\hline
\end{tabular}

\subsection{Respondents' Perception of the Adoption and Use of Technology by SMEs}

In order to assess the perceptions of respondents towards adoption and use of technology by SMEs, a five point likert-type scale with 15 items ranging from 1 (strongly disagree) to 5 (strongly agree) was constructed. The respondents were asked to indicate their perception by circling the appropriate answer. The percentages and means of responses were then calculated as show in table 4 .

Table 4. Descriptive Statistics of respondents' perceptions of the adoption and use of technology by SMEs

\begin{tabular}{|c|c|c|c|c|c|c|c|}
\hline Variable & $\mathrm{SD}(\%)$ & $\mathrm{D}(\%)$ & $\mathrm{N}(\%)$ & $\mathrm{A}(\%)$ & $\mathrm{SA}(\%)$ & Mean & St.d \\
\hline Improve productivity & 2.63 & 3.16 & 14.72 & 58.07 & 21.42 & 4.34 & 0.87 \\
\hline Improve customer satisfaction & 5.72 & 11.53 & 17.32 & 34.57 & 30.86 & 3.78 & 0.92 \\
\hline Keep up with competitors & 4.78 & 6.92 & 21.63 & 36.34 & 30.33 & 4.17 & 0.84 \\
\hline Improve working on joint projects with others & 7.23 & 15.34 & 36.72 & 31.61 & 9.01 & 3.42 & 0.97 \\
\hline Improves communication with suppliers & 8.92 & 9.23 & 32.71 & 27.43 & 21.71 & 3.27 & 0.89 \\
\hline Increase operational efficiency & 3.68 & 7.26 & 15.98 & 46.72 & 26.36 & 4.47 & 0.82 \\
\hline Increase staff satisfaction & 11.82 & 13.67 & 17.21 & 29.73 & 27.57 & 3.67 & 0.91 \\
\hline Creates jobs & 1.76 & 6.86 & 11.75 & 21.76 & 57.87 & 4.76 & 0.99 \\
\hline Working with technology is enjoyable & 13.89 & 17.34 & 36.65 & 19.72 & 12.40 & 2.89 & 0.78 \\
\hline Puts more works on shoulders of staff & 35.62 & 29.56 & 17.48 & 10.16 & 7.18 & 1.32 & 0.67 \\
\hline Technological tools are difficult to use & 27.89 & 41.87 & 16.76 & 7.82 & 5.66 & 2.13 & 0.82 \\
\hline Technology relieves staff from daily work & 38.23 & 31.65 & 11.78 & 11.21 & 7.13 & 1.41 & 0.69 \\
\hline Knowledge on how to use technology is difficulty & 21.47 & 36.74 & 14.63 & 12.36 & 14.80 & 2.31 & 0.86 \\
\hline Use of technology is waste of time & 48.56 & 31.98 & 12.72 & 3.57 & 3.17 & 1.07 & 0.62 \\
\hline Use of technology can reduce personal treatment of customers & 29.37 & 31.25 & 21.21 & 11.63 & 6.54 & 2.17 & 0.79 \\
\hline
\end{tabular}

Note. $\mathrm{SD}=$ strongly disagree; $\mathrm{D}=$ disagree; $\mathrm{N}=$ no opinion; $\mathrm{A}=$ agree; $\mathrm{SA}=$ strongly agree. 
As shown in table 4, the mean of responses in the suggestion that adoption and use of technology will improve productivity of SMEs was 4.34 (St.D $=0.87$ ) which tended to 4 , meaning that majority of respondents' agreed adoption and use of technology by SMEs will improve their productivity. On the suggestion that technology will improve customer satisfaction, the mean of responses was $3.78(S t . D=0.92)$ which was approximately 4 meaning that respondents agreed that implementation of technology by SMEs in their business will improve customer satisfaction. The majority of respondents also agreed that technology can help keep up with competition (Mean of responses 4.17, St.D $=0.84$ ), working with technology can increase operational efficiency (mean of responses 4.47, St.D =1.82) and increase staff satisfaction (mean of responses 3.67, St.d $=0.91$ ). An overwhelming majority of respondents strongly agreed that technology can create jobs, with a mean of 4.76 $(\mathrm{St} . \mathrm{D}=0.99)$ which was approximately 5 . These findings were consistence with the finding of a study done by Mingaine, (2013) that concluded adoption and use of technology improved management of SMEs as well enhancing their performance.

With suggestion that working with technology is enjoyable (mean of responses 2.89 , St.D $=0.78$ ), improve working on joint projects with other sectors (mean of responses 3.42, St.D $=0.97$ ) and improves communication with suppliers (mean of responses 3.27, St.D $=0.89$ ), all which tended towards 3 , this meant that respondents had no idea that working with technology was enjoyable, improves joint ventures or improved communication with suppliers. These findings were attributed to the fact that most of SMEs in Cote d'Ivoire had not fully embraced use of technology; hence they did not have views of its importance.

On the suggestion that technology puts more works on shoulders of staff (mean of responses 1.32, St.d $=0.67$ ), relieves staff from daily work (mean of responses 1.41 , St.D $=0.69$ ) and working with technology is waste of time (mean of responses $1.07, \mathrm{St} . \mathrm{D}=0.62$ ). All these responses were approximately 1 , meaning that respondents strongly disagreed that technology puts more works on shoulders of staff, relieves staff from daily work and working with technology was waste of time. The findings are in agreement with Onyango et al, (2014) who found in a study of SMEs in Kenya, that use of technological tools helped CEO and staffs of SMEs execute their duties effectively and they used them for enhancing business performance.

With an assertion that technological tools are difficult to use (mean of responses 2.13, St.D $=0.82$ ) and use of technology can reduce personal treatment of customers (mean of responses 2.17 , St.D $=0.79$ ), majority of respondents disagreed that technological tools are difficult to use and technology can reduce personal treatment of customers.

In short, these finding revealed that CEOs and workers of SMEs had positive perceptions towards adoption and use of technology.

\subsection{The Extent of Adaption and Use of Technology by SMEs}

Respondents were encouraged to indicate to which extent they used technological tools (computers, phones, printers, internet, etc) in their businesses either on a daily or weekly basis. As shown by table 5, majority (153 out of 200 respondents, making 76.5\%) indicated that their businesses used technology, not at all or to less extend.

Table 5. The extend of adoption and use of technology by SMEs

\begin{tabular}{lll}
\hline Extend & No. & $\%$ \\
\hline Not at all & 99 & 49.5 \\
To less extend & 54 & 27.0 \\
To average extend & 23 & 11.5 \\
To some extend & 15 & 7.5 \\
To greater extend & 9 & 4.5 \\
\hline
\end{tabular}

As indicated in table 5, the data suggest that though respondents' perceptions towards technology were positive (as shown in table 4), adoption and use of the technology was not effectively being utilized by SMEs. A test of relationship between perception of technology adoption and use by SMEs and extent of technology usage show a weak positive linear regression $(r=2.23, r 2=4.97, \alpha=0.07$ and $\beta=2.23)$ with a linear regression model. Extent of technology adoption and use by SMEs $=0.07+2.23$ perception of technology adaption and use by the businesses. From this analysis, it can be argued that this relationship is weak because only $10.23 \%$ of extent of technology usage can be attributed to perception of technology adoption and use by SMEs. This as an 
implication that "positive perception of technology adoption and use" does not automatically result to greater extent of usage.

\subsection{Barriers to Adoption and Use of Technology by SMEs}

On closed ended questions, respondents were asked to identify the barriers that they encountered when adopting and using technology in their businesses. Table 5 summarizes the main responses.

Table 6. Barriers to adoption and use of technology by SMEs

\begin{tabular}{lll}
\hline Barrier & No. & $\%$ \\
\hline Cost of technological tools & 194 & 97.0 \\
Lack of technological skills & 191 & 95.5 \\
Uncertainty over business benefits & 183 & 91.5 \\
Technical problems, like breakdowns & 176 & 88.0 \\
Inadequate infrastructure and poor maintenance & 162 & 81.0 \\
Limited access to internet & 157 & 78.5 \\
Limited and unreliable sources of power & 144 & 72.0 \\
Negative attitude towards technology & 129 & 64.5 \\
Limited support by government and other agencies & 103 & 51.5 \\
\hline
\end{tabular}

As shown in table 6, majority of respondents $(97.0 \%)$ indicated that the major barrier to adoption and use of technology by SMEs was cost of technological tools such as computers, printers, mobile phones, internet, projectors, etc. The other barrier was indicated by $191(95.5 \%)$ as lack of technological skills, while 183 (91.5\%) perceived uncertainty over business benefits from adoption and use of technology as main challenged encountered by SMEs. These findings are in agreement with Alila \& Ove, (2011) who found that due to poverty majority of population in Africa were unable to acquire and own ICT tools needed in executing businesses.

Technical problems (like breakdowns) were perceived by $176(88 \%)$ as a barrier, while $162(81.0 \%)$ indicated that inadequate infrastructure and poor maintenance was challenges experienced during implementation of technology by SMEs. Limited access to internet was viewed by 157 (78.5\%) as a barrier. These findings were in line with results of study conducted by Ruffling (2012) that concluded that due to breakdowns and poor maintenance of ICT tools, many business people in Africa were unable to utilize the full benefits of the technology.

Limited and unreliable source of power (electricity, generators, etc) was perceived by 144 (72.0\%) as barrier to adoption and use of technology by SMEs in Cote d'Ivoire. A report by the Index of Economic Freedom (2014) had the same bearing, where it was reported that in most regions of the country, connections to national electricity grid was not yet realized. Further, respondents felt that negative attitude towards technology (64.5\%), was contributing to impediments on adoption and use of technology as well as limited support offered by the government and other agencies 103(51.5\%). OECD (2008) reported that banks were limiting loans advanced to SMEs due to uncertainty of their businesses. This could explain why a number of respondents felt that government and other agencies (like banks) did not support them in terms of adoption and using technology.

\subsection{Suggestions by Respondents to Overcome Barriers to Adoption and Use of Technology by SMES}

The respondents who participated in this study suggested some valuable recommendations on how to overcome barriers affecting adoption and use of technology by SMEs.

Table 7. Suggestions on how to overcome barriers in adoption and use of technology

\begin{tabular}{lll}
\hline Suggestion & No. & $\%$ \\
\hline Expanding funding to SMEs in order to upgrade technology & 167 & 83.5 \\
Training more IT technicians through opening more training centers & 151 & 75.5 \\
Reducing cost of technological infrastructure by lowering tax charged on them & 149 & 74.5 \\
Setting proper Government policies/regulations on adoption and use of technology & 135 & 67.5 \\
Developing support mechanisms that can train SMEs on usage of technology & 128 & 64.0 \\
Creating awareness of opportunities offered by technology in SMEs & 117 & 58.5 \\
Sharing of technology infrastructure among businesses & 101 & 50.5 \\
\hline
\end{tabular}


As indicated in table 7, one hundred and sixty seven (83.5\%) suggested expanding funding to SMEs in order to upgrade technology. This finding had indication that most concerns of the respondents were the fear of technology becoming obsolete, hence requiring frequent updates. Indeed, in the highly competitive and cash-poor context in which SMEs operates, concerns in funding for updates was a real one. Training of more IT technicians through opening of more training centers was recommended by one hundred and fifty one (75.5\%). SMEs frequently encounter operational problems with technology exacerbating their reliance on external vendors or consultants. Therefore, this finding had indication that with more trained IT experts, SMEs can tab from their expertise in adoption and use of technology. Reducing cost of technological infrastructure by lowering tax charged on them was suggested by149 (74.5\%), government to set proper policies and regulations on adoption and use of technology was proposed by 135 (67.5\%), developing support mechanisms that can train SMEs on usage of technology was suggested by128 (64.0\%), while creating awareness of opportunities offered by technology in SMEs was suggested by $117(58.5 \%)$ and sharing of technology infrastructure among businesses was proposed by 101(50.5\%). These findings were in agreement with reports of IORPEV (2013) and INIE (2013) which reported that government to expand training in technology use to all sectors and create awareness of the potential of technology to small and medium businesses in the country.

\section{Conclusions and Recommendations}

This study was aimed at providing an assessment on the factors holding sway and possible solutions available during adoption and use of technology by SMEs. From the study, it appears that most of SMEs CEOs and employees were positive with adoption and use of technology by their businesses; they appreciated use of technology to enhance their profit margins and increase business performance. The CEOs and employees interest, championing and commitment of adoption and use of technological tools positively influenced the whole process. However, from the study, it appeared most of SMEs were not using technology properly as was reported by most participants who indicated that they never used technological tools or used them to less extend. The study revealed there were barriers that affected smooth adoption and use of technology by SMEs. These barriers were identified as cost of technological tools, lack of technological skills, uncertainty over business benefits from adoption and use of technology, technical problems (like breakdowns), inadequate infrastructure and poor maintenance, limited access to internet, limited and unreliable sources of power, among others.

As a result of findings from this study, the following recommendations are made. The government through ministries of Information, Technology, Trade and Labor should support and initiate training programs to develop capacity of SMEs in technological tools like internet, computers, mobile phones, printers, etc. Induction sessions and seminars should be regularly held by stakeholders to allow SMEs to evaluate new technological inventions. Government and other stakeholders should create deliberate programs to make awareness on the potential of technologies in SMEs. SMEs should start investing in basic technological tools to help improve their management practices in line with global trends. By doing this, SMEs will be more competitive and be able to access global markets. Stakeholders and other government agencies should establish a close working relationship with all SMEs, where they can get continuous feedback in order to identify problems areas. The government should formalize and finalize policies and regulations along with the required legislation for effective implementation of actions to rectify problems areas affecting SMEs adoption and use of technology. This should go beyond general regulations and policy formulations by including designing an elaborate incentive package for investments, pro-active policy interventions, technology transfer and entrenching competition. The current study has drawn conclusions about adoption and use of technology in SMEs and has laid a foundation for further studies to be undertaken. Further studies should be on types of technology appropriate to specific SMEs and their business model. Future studies should examine understanding and knowledge of SMEs on government regulations and enforcement of technological laws.

\section{References}

African Development Bank. (2004). Enhancing development in Africa: African women in Small and Medium size business, the continents hidden growth reserves.

Alila, O., \& Ove, P. (2011). Negotiating social space: East African micro enterprises. African World Press.

Barua, A. (2011). Information Technologies and business value: An analytic and empirical investigation. Information Systems Research, 6(1), 3-23.

Bates, T. (2011). Analysis of survival rates among franchise and independent small business startups. Journal of Small Business Management, 33(2), 26-36. 
Berger, A. (2012). Radio Frequency Identification, Interactive Marketing. Journal of Small Business Management, 6(4), 346-357.

Dixon, T., Thompson R., \& McAllister, P. (2012). The Value of ICT for MSEs in the UK: A Critical Literature Review. College of Estate Management, Reading.

Gay, R. (2002). Educational research: Competencies for analysis and application (7th ed.). Upper Saddle River, NJ: Pearson Education.

Ghimire, B., \& Abo, R. (2013). An empirical investigation of Ivorian SMEs access to bank finance: Constraining factors at demand-level. Journal of Finance and Investment Analysis, 2(4), 29-55.

Giovanni, F., \& Mario, A. (2013). Small company attitude towards ICT based solutions: some key-elements to improve it. Educational Technology \& Society, 2(3) 37-49.

Green, N. (2011). Personas of E-commerce adoption in small businesses in New Zealand. Journal of Electronic Commerce in Organizations, 4(3), 17-45.

Iacovou, C., \& Benbasat, D. (2009). Electronic Data Interchange and Small Organizations: Adoption and Impact of Technology. MIS Quarterly, 19(4), 121-163.

IEF (Index of Economic Freedom). (2014). Cote d'Ivoire. Retrieved from http://www.heritage.org/index/country/cotedivoire

INIE (Instititut Ivoirien de l'Entreprise). (2013). Espace des PMEs en Cote d'Ivoire. Retrieved from http://www.inie.ci/_pme/log_pme.php?lien=C

Kirby, D., \& Turner, M. (2012). IT and the small retail business. International Journal of Retail and Distribution Management, 21(7), 20-27.

Koul, Y. (2012). Case Study Research: Design and Methods (2nd ed.). Thousand Oaks, CA: Sage Publications.

Kozak, R. (2011). Small and Medium Forest Enterprises: Instruments of change in the developing world. University of British Columbia.

Matlay, H. \& Westhead, P. (2013). Virtual teams and the rise of e- entrepreneurship in Europe. International Small Business Journal, 23(3), 279-300.

Mingaine, L. (2013). Challenges encountered by Principals during implementation of ICT in public secondary schools, Kenya. Journal of Sociological Research, 4(2) 1-19.

Muraya, P. (2006). Urban Planning and Small-Scale Enterprises in Nairobi Kenya. Habitat International, 30(1), $127-143$.

Mutwiri, I., \& Mingaine, L. (2014). The value addition on bananas in Kenya: Strategies to benefit producers and satisfy consumers. The International Journal's Research Journal of Economics and Business Studies, 3(5), $106-117$.

Onyango, R., Ongus, W., Awuor, F., \& Nyamboga, C. (2014). Impacts of adoption and use of mobile phone technology on the performance of Micro and Small enterprises in Kisii municipality Kenya. World Journal of Computer Application and Technology, 2(2), 34-42. http://dx.doi.org/10.13189/wjcat.2014.020202

Orodho, A. (2008). Research Methods. Nairobi: Kenyatta University, Institute of Open Learning.

Parker, O. (2010). Exploring the Usage and Impact of "Transformational" Mobile Financial Services: The Case of M-PESA in Kenya. Journal of Eastern African Studies, 3(3), 509-525.

Paul, D., \& Pascale, D. (2013). Information Technology and Economic Development: An Introduction to the Research Issues. Research Paper. Los Angeles, CA: Sage.

Premkumar, G., \& Roberts, M. (2010). Adoption of new information technologies in rural small businesses. The International Journal of Management Science, 27(4), 467-484.

Reynolds, P. (2010). Your Own Business: A Practical Guide to Success. New York: McGraw Hill.

Ritchie, B., \& Brindley, C. (2010). ICT adoption by MSEs: Implications for relationships and management. New Technology, Work and Employment, 20(3), 205-217.

Sakai, K. (2012). Enhancing Manufacturing Performance with ERP Systems. Information Systems Management, 17(3), 1-13. 
Thiam, I. (2009). Unlocking the potential of Small and Medium size Enterprises in West Africa: A path for reform and action. Master thesis, Russian Friendship University.

Thong, J., \& Yap, C. (2011). CEO characteristics, organizational characteristics and information technology adoption in small business. International Journal of Management Science, 23(4), 429-442.

Vilaseca, J. (2013). Las TIC y las transformaciones de la empresa catalane. Barcelona: Foundation for the Open University of Catalonia.

\section{Copyrights}

Copyright for this article is retained by the author(s), with first publication rights granted to the journal.

This is an open-access article distributed under the terms and conditions of the Creative Commons Attribution license (http://creativecommons.org/licenses/by/3.0/). 